\title{
Graft Copolymer (Guar Gum-G-Poly 2-Acrylamidoglycolic Acid): Synthesis, Swelling and Flocculation Behaviors
}

\author{
Vijay Shankar Pandey ${ }^{1}$, Brajesh Kumar Shukla ${ }^{2}$, Mithilesh Yadav ${ }^{3}$, \\ ${ }^{1}$ Department of Chemistry, S. V. M. Science \& Technology P. G. College, Pratapgarh, Uttar Pradesh, India \\ ${ }^{2}$ Department of Chemistry, University of Allahabad, Allahabad, India \\ ${ }^{3}$ Department of Chemistry, Jamia Millia Islamia, New Delhi, India \\ Email address: \\ mithileshau@gmail.com (M. Yadav) \\ ${ }^{*}$ Corresponding author
}

\section{To cite this article:}

Brajesh Kumar Shukla, Vijay Shankar Pandey, Mithilesh Yadav. Graft Copolymer (Guar Gum-G-Poly 2-Acrylamidoglycolic Acid): Synthesis, Swelling and Flocculation Behaviors. International Journal of Biochemistry, Biophysics \& Molecular Biology.

Vol. 2, No. 2, 2017, pp. 10-15. doi: 10.11648/j.ijbbmb.20170202.11

Received: March 10, 2017; Accepted: July 13, 2017; Published: August 1, 2017

\begin{abstract}
The present paper reports the modification of guar gum through the grafting of 2-acrylamidoglycolic acid by free radical polymerization using an efficient potassium peroxydiphosphate/thioacetamide redox system in nitrogen atmosphere. The reaction conditions for maximum grafting have been optimized by varying the reaction variables including the concentration of 2-acrylamidoglycolic acid $\left(5.3 \times 10^{-2} \mathrm{~mol} \mathrm{dm}^{-3}\right)$, potassium peroxydiphosphate $\left(1.2 \times 10^{-2} \mathrm{~mol} \mathrm{dm}^{-3}\right)$, thioacetamide (TA) $\left(2 \times 10^{-3} \mathrm{~mol} \mathrm{dm}^{-3}\right)$, sulphuric acid $\left(4 \times 10^{-3} \mathrm{~mol} \mathrm{dm}^{-3}\right)$, guar gum $\left(1 \mathrm{~g} \mathrm{dm}^{-3}\right)$ along with time duration $(150$ min) and temperature $\left(35^{\circ} \mathrm{C}\right)$. Water swelling capacity and flocculation and studies of synthesized graft copolymer have been performed with respect to the parent polymer. The graft copolymer has been characterized by Fourier transform infrared spectroscopy and thermogravimetric analysis.
\end{abstract}

Keywords: Graftcopolymer, Fourier Transform Infrared Spectroscopy, Thermo Gravimetric Analysis

\section{Introduction}

Modification of natural polymers by grafting has drawn much attention in recent years [1-5]. Guar gum (GG) is derived from the seeds of guar plant Cyanaposis tetragonolobus (Leguminosae); it is a natural nonionic branched polymer with $\beta$-D-mannopyranosyl units linked $1-$ 4 with single membered $\alpha$-D-galactopyranosyl units occurring as side branches. GG and their derivatives have been used in many areas (e.g. thickening agent, ion exchange resin and suspending agent etc.). It forms colloidal dispersions with water at room temperature and imparts extraordinary viscosity, because of this property, native guar gum as well as its derivatives are commercially imparting and find use in such diverse applications like oil well drilling, paper and textile sizing, as a binding agent for explosives, and is widely used in food industry [6]. Guar gum crosslinked with borax was investigated for water retention applications [7]. Although guar gum has wide industrial applications, it suffers from some draw backs like biodegradability [8], which limits its uses considerably. These drawbacks can be improved through the grafting of vinyl monomer, which imparts new properties to the polymeric backbone. Grafting provides an efficient route not only removing the drawback but also improving its properties towards swelling and flocculation. Up to date many investigations have been carried out in view of preparing biopolymer-base advanced materials, but reports on grafting onto the guar gum are scantily available in the light of its versatile applications. This work is carried out with an aim to tailor guar gum based hybrid material by grafting of 2acrylamidoglycolic acid, which is hydrophilic and biocompatible in nature [9-10]. 2-Acrylamidoglycolic acid (AGA) refers to a class of acrylamides containing - $\mathrm{OH},-$ $\mathrm{COOH}$ and $-\mathrm{CONH}-$ functional groups that shows excellent selectivity in separating apatite from siliceous gangue [11]. A number of copolymers have also been recognized to have ability to respond to several stimuli [12] and to recover metal ions [13-14]. Taking in mind all of these fascinating applications of acrylamidoglycolic acid (AGA) and guar 
gum, an attempt has been made to graft acrylamidoglycolic acid (AGA) onto guar gum. The resulting graft copolymer shows better enhancement in the properties towards waterswelling capacity, and flocculation than initial polymer.

\section{Experimental}

\subsection{Materials}

Guar gum (Sigma-Aldrich, U. S. A.), 2Acrylamidoglycollic acid (Sigma), Potassium Peroxymonosulphate (Sigma), sulphuric acid (E. Merck) and Thioacetamide (E. Merck) were purchased and used as such. All the solutions were prepared in deionized water. For the flocculation and coking coals were received from steel plant Bokaro, India.

\subsection{Procedure for Graft Copolymerization}

The calculated amount of GG, AGA, TA, sulphuric acid has been added to three neck reactor at a fix temperature and a slow stream of nitrogen gas is passed. After 30 min., a known amount of deoxygenated PMS solution is added to initiate the reaction. After desired time period, the reaction was stopped by letting air into the reactor. The grafted sample has been precipitated by pouring it in to water/methanol mixture (ratio 1:5). The obtained grafted part has been filtered, dried and weighed. Further, the homopolymer can be prepared by the procedure of my previous published research paper [15]

\section{Results and Discussion}

The graft copolymer has been characterized as reported in the literature [16-17].

$$
\begin{gathered}
\text { Grafting ratio }(\% \mathrm{G})=\frac{\text { Grafted polymer }}{\text { Weight of substrate }} \times 100 \\
\text { Grafting efficiency }(\% \mathrm{E})=\frac{\text { Polymer in graft }}{\text { Polymer formed }} \times 100 \\
\text { Homopolymer }(\% \mathrm{H})=100-\% \text { Grafting efficiency }
\end{gathered}
$$

\subsection{Characterization of Graft Copolymer (GG -g- 2-Acrylamidoglycolic Acid)}

The IR spectra of guar gum and grafted samples have been recorded with JASCO FT/ IR-5300 model in the range 500 to $4000 \mathrm{~cm}^{-1}$. The thermal stability of the films was investigated using a thermal analyzer instrument (TGA 4000 Perkin Elmer) from $35^{\circ} \mathrm{C}$ to $850^{\circ} \mathrm{C}$ under a nitrogen atmosphere at a heating rate of $20^{\circ} \mathrm{C} / \mathrm{min}$.

\subsection{Determination of Optimum Grafting Conditions}

The optimum reaction conditions for maximum percentage of GG-g-2-acrylamidoglycolic acid by using PMS/thioacetamide redox system in the presence of hydrogen ion $\left(\mathrm{H}^{+}\right)$have determined.

\subsection{Effect of [Thioacetamide], [Peroxymonosulphate] and [2-Acrylamidoglycolic Acid] Concentration}

The variation of thioacetamide (TA) concentration from $0.4 \times 10^{-3}$ to $3.6 \times 10^{-3} \mathrm{~mol} \mathrm{dm}^{-3}$ reveals that of grafting ratio and efficiency increase on increasing the thioacetamide concentration up to $2.0 \times 10^{-3} \mathrm{~mol} \mathrm{dm}^{-3}$ due to availability of more primary free radicals $\left(\mathrm{R}^{\bullet}=\mathrm{R}_{1} \mathrm{~S}^{\bullet}\right.$ and $\left.\mathrm{SO}_{4}^{\bullet}\right)$, which is formed due to reduction of peroxymonosulphate by thioacetamide [18]. However, on further increasing the concentration of thioacetamide from $2 \times 10^{-3}$ to $3.6 \times 10^{-3} \mathrm{~mol}$ $\mathrm{dm}^{-3}$, the decrement in grafting parameters has been found which is probably due to premature termination of 2acrylamidoglycolic acid radicals giving rise to the formation of more homopolymer. The results are represented by Table 1 .

Table 1. Effect of Variation in Used Chemicals on Grafting Parameters.

\begin{tabular}{lllll}
\hline Chemicals & Variation in data & $\mathbf{\% G}$ & $\mathbf{\% E}$ & $\mathbf{\% H}$ \\
\hline & 0.4 & 168.0 & 60.87 & 39.13 \\
& 1.2 & 195.0 & 62.71 & 37.29 \\
{$[\mathrm{TA}] \times 10^{3}$} & 2.0 & 216.8 & 64.37 & 35.63 \\
$(\mathrm{~mol} \mathrm{dm}-3)$ & 2.8 & 175.0 & 57.80 & 42.20 \\
& 3.6 & 130.0 & 51.92 & 48.08 \\
& 0.4 & 130.0 & 51.18 & 48.82 \\
& 0.8 & 180.0 & 59.02 & 40.98 \\
{$[\mathrm{PMS}] \times 102$} & 1.2 & 216.8 & 64.37 & 35.63 \\
$(\mathrm{~mol} \mathrm{dm}-3)$ & 1.6 & 160.0 & 56.94 & 43.06 \\
& 2.0 & 110.0 & 47.29 & 52.71 \\
& 2.7 & 145.0 & 32.39 & 67.61 \\
& 4.0 & 190.0 & 60.90 & 39.10 \\
\hline AGA $] \times 102$ & 5.3 & 216.8 & 64.37 & 35.63 \\
$(\mathrm{~mol} \mathrm{dm}-3)$ & 6.7 & 125.0 & 51.44 & 48.56 \\
& 8.0 & 95.0 & 42.22 & 57.78 \\
\hline
\end{tabular}

$[\mathrm{TA}]=2 \times 10^{-3} \mathrm{~mol} \mathrm{dm}^{-3},[\mathrm{GG}]=1 \mathrm{gm} \mathrm{dm}^{-3},[\mathrm{AGA}]=5.3 \times 10^{-2} \mathrm{~mol} \mathrm{dm}^{-3}$, $\left[\mathrm{H}^{+}\right]=4 \times 10^{-3} \mathrm{~mol} \mathrm{dm}^{-3}$, [PMS $]=1.2 \times 10^{-2} \mathrm{~mol} \mathrm{dm}^{-3}$, Time $=2.5 \mathrm{~h}$, $\mathrm{Temp}=35^{\circ} \mathrm{C}$

The effect of peroxymonosulphate ion concentration on grafting reaction has been studied and the results were summarized in Table 1. It was observed that grafting ratio, and efficiency were increased on increasing throughout the cited range i.e. from $0.4 \times 10^{-2}$ to $1.2 \times 10^{-3} \mathrm{~mol} \mathrm{dm}^{-3}$. This behavior might be attributed due to progressive reduction of PMS by thioacetamide producing primary free radicals, which attack the guar gum molecules creating more active sites, to which monomer addition takes place.

The effect of concentration of 2-acrylamidoglycolic acid on grafting parameters has been investigated by varying the concentration of 2-acrylamidoglycolic acid (AGA) from $2.7 \times 10^{-2}$ to $8.0 \times 10^{-2} \mathrm{~mol} \mathrm{dm}{ }^{-3}$. It has been observed that grafting ratio and efficiency increase on increasing the concentration up to $5.3 \times 10^{-2} \mathrm{~mol} \mathrm{\textrm {dm } ^ { - 3 }}$ and thereafter, grafting parameters decrease (Table 1). However the formation of homopolymer shows a reverse trend with respect to grafting efficiency. This behavior is attributed to accumulation of monomer molecules at close proximity of polymeric backbone. The monomer molecules, which are at the immediate vicinity of reaction sites, become acceptors of 
guar gum macro radicals resulting in chain initiation and thereafter themselves become free radical donor to the neighboring molecules leading lower of termination. But on further increasing the concentration of 2-acrylamidoglycolic acid, the grafting parameters decrease due to formation of more homopolymer.

Furthermore, the used guar gum and sulphuric acid concentration in are $1 \mathrm{gm} \mathrm{dm}^{-3}$ and $4 \times 10^{-3} \mathrm{~mol} \mathrm{dm}^{-3}$, respectively. The optimum time and temperature for graftcopolymerization are $150 \mathrm{~min}$. and $35^{\circ} \mathrm{C}$, respectively.

\subsection{Evidence of Grafting}

The grafting of 2-acrylamidoglycolic acid on guar gum has been confirmed by FTIR and TGA.

\subsection{IR Spectroscopy}

IR spectra of guar gum [19] have been recorded in the range of $500-4000 \mathrm{~cm}^{-1}$. IR spectrum of guar gum (Figure 1) shows characteristic absorption bands arising from $\mathrm{OH}$ stretching (broad) near $3019.97 \mathrm{~cm}^{-1}$. On comparing the spectra of both, guar gum and its graft copolymer, GG-gAGA (Figure 2) shows a sharp band at $3462 \mathrm{~cm}^{-1}$. The sharpness of band indicates the participation of hydroxyl groups in chemical reaction. The graft copolymerization is further confirmed by characteristic absorption band of amide I at $1670 \mathrm{~cm}^{-1}$ due to $\mathrm{C}=\mathrm{O}$ stretching vibration, and at 1390 $\mathrm{cm}^{-1}$ due to-CN stretching vibration of AGA molecule, respectively. The appearance of additional peaks in spectrum of graft copolymer and shifting of $-\mathrm{OH}$ stretching vibration appeared in the spectrum of guar gum from the spectrum of guar gum -g-2-acrylamidoglycolic acid showed that grafting might have taken place on $\mathrm{OH}$ sites of guar gum.

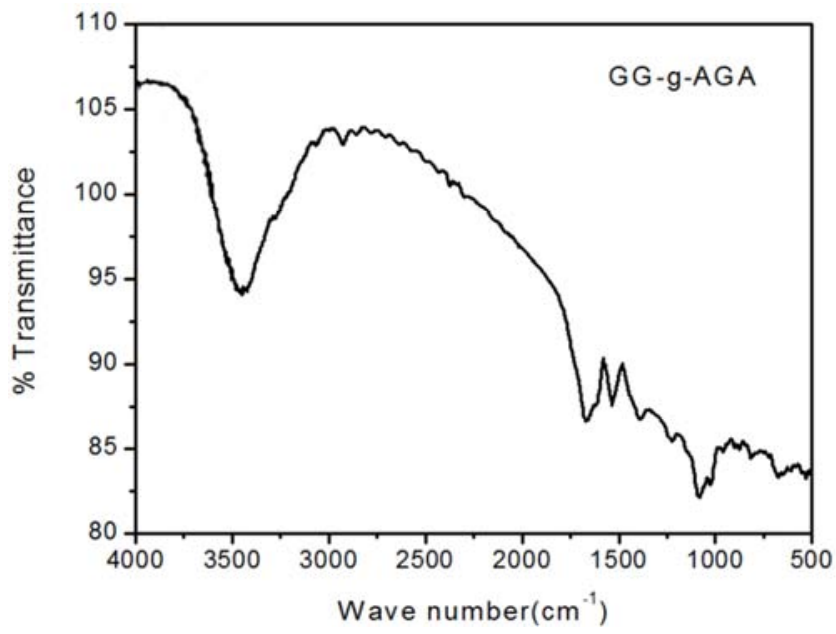

Figure 1. IR spectrum of guar gum-g-poly 2-Acrylamidoglycolic acid.

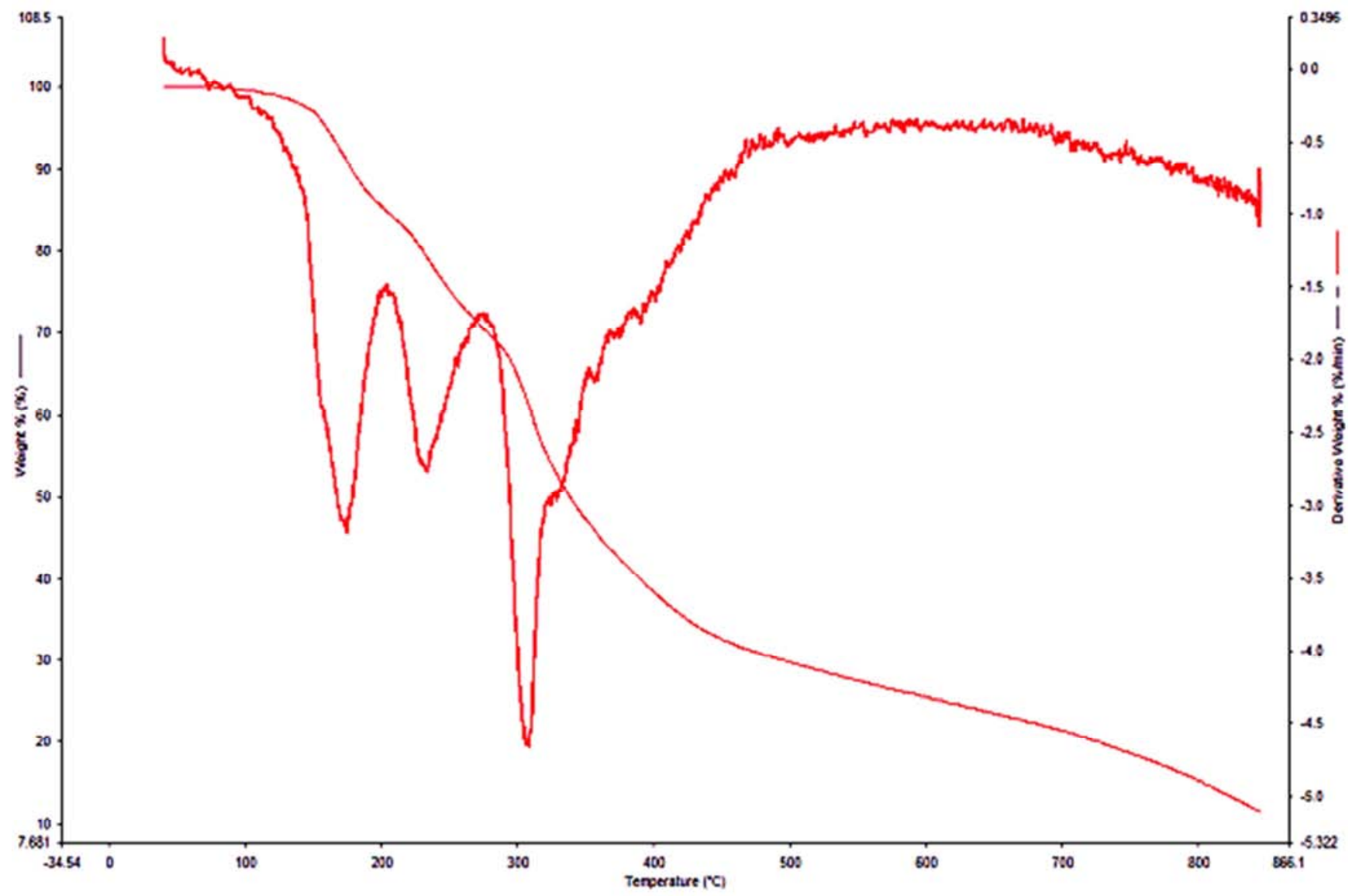

Figure 2. Thermogravimetric trace of guar gum-g-poly 2-Acrylamidoglycolic acid. 


\subsection{Thermogravimetric Analysis}

The integral procedure decomposition temperature (IPDT) proposed by Doyle [20] has been correlated the volatile parts of polymeric materials and used for estimating the inherent thermal stability of polymeric materials [21-22]. The IPDT value were calculated by using our recent published research paper [23]. The detailed explanation of thermogravimetric analysis (TGA) behavior of guar gum has been interpreted in our previous published papers [24]. The integral procedural decomposition temperature (IPDT) is $447^{\circ} \mathrm{C} . \mathrm{T}_{\max }$, the temperature at which maximum degradation occurred, is $300^{\circ} \mathrm{C}$ and final decomposition temperature (FDT) has been observed at about $385^{\circ} \mathrm{C}$.

The degradation of GG-g-AGA shows three step degradations. It has been found that degradation of GG-gAGA starts at about $100^{\circ} \mathrm{C}$ temperature (Figure 2). The rate of weight loss increases with increase in temperature from $110^{\circ} \mathrm{C}$ to $155^{\circ} \mathrm{C}$ and thereafter decreases and attains maximum at about $450^{\circ} \mathrm{C}$. First, second and third $\mathrm{T}_{\max }$ has been found at $181^{\circ} \mathrm{C}, 240^{\circ} \mathrm{C}$ and $305^{\circ} \mathrm{C}$, respectively. The integral procedural decomposition (IPDT) and final decomposition temperature (FDT) have been found at about $549.62^{\circ} \mathrm{C}$ and $500^{\circ} \mathrm{C}$ respectively. The above results confirmed that GG-g-AGA is more thermally stable than guar gum on the basis of their respective IPDT value.

\subsection{Swelling Studies}

The graftcopolymer (GG-g-AGA) samples $(0.10 \mathrm{~g})$ were put into a weighed teabag and immersed in $100 \mathrm{~mL}$ distilled water and allowed to soak for $24 \mathrm{~h}$ at room temperature. The equilibrated swollen sample was allowed to drain by removing the teabag from water and hanging until no drop drained $(\sim 2 \mathrm{~h})$. The bag was then weighed to determine the weight of the swollen sample. The absorbency (equilibrium swelling) was calculated using the following equation [2527]:

$$
\text { Absorbency }=\left(\mathrm{W}_{\mathrm{s}}-\mathrm{W}_{\mathrm{d}}\right) / \mathrm{W}_{\mathrm{d}}
$$

Where $\mathrm{W}_{\mathrm{s}}$ and $\mathrm{W}_{\mathrm{d}}$ are the weights of the swollen and the dry sample, respectively. So, absorbency was calculated as grams of water per gram of graftcopolymer $(\mathrm{g} / \mathrm{g})$. The accuracy of the measurements was $\pm 3 \%$.

Table 2. Swelling Capacity of Graftcopolymers.

\begin{tabular}{lllll}
\hline Sample code & {$[\mathbf{A G A}] \times \mathbf{1 0}^{\mathbf{2}} \mathbf{~} \mathbf{m o l} \mathbf{~ d m}^{-3}$} & $\mathbf{\% G}$ & $\mathbf{P}_{\mathbf{S}}$ & $\mathbf{S}_{\mathbf{R}}$ \\
\hline A & 2.6 & 145.0 & 150 & 1.50 \\
B & 4.0 & 190.0 & 180 & 1.80 \\
C & 5.3 & 216.8 & 220 & 2.20 \\
D & 6.6 & 125.0 & 120 & 1.20 \\
E & 8.0 & 95.0 & 110 & 1.10 \\
\hline
\end{tabular}

A,B,C,D,E indicates the sample of graft copoymer (GG-g-AGA)

${ }^{* *}$ Swelling capacity of graft copoymer (GG-g-AGA)

$[\mathrm{TA}]=2 \times 10^{-3} \mathrm{~mol} \mathrm{dm}^{-3},[\mathrm{GG}]=1 \mathrm{~g} \mathrm{dm}^{-3},[\mathrm{AGA}]=5.3 \times 10^{-2} \mathrm{~mol} \mathrm{dm}^{-3},[\mathrm{H}+]$

$=4 \times 10^{-3} \mathrm{~mol} \mathrm{dm}^{-3},[\mathrm{PMS}]=1.2 \times 10^{-2} \mathrm{~mol} \mathrm{dm}^{-3}$, Time $=2.5 \mathrm{~h} \mathrm{Temp}=35^{\circ} \mathrm{C}$
The results of swelling studies reveal that swelling of graft copolymer is dependent upon percent grafting. The dependence of the swelling capacity of graftcopolymers on 2acrylamidoglycollic acid (AGA) concentration is illustrated in Table 2. In graftcopolymer, after water absorbency, with increase in the AGA concentration their swelling capacity increased, reaching the maximum value of swelling capacity. The increase in swelling capacity may originate from the greater availability of monomer molecules in the vicinity of the chain propagating sites of guar gum radicals. It has been observed that a maximum percent swelling of $220 \%$ is obtained when grafting ratio is $216.8 \%$.

\subsection{Flocculation Study}

The flocculation performance of Guar Gum is GG-g-AGA has been studied by Jar test method. The beaker was placed on flocculator dipping the stirrer blade in the suspension. Under a low stirring condition, required quantity of polymer solution was added to beaker to make predetermined dose with respect of suspension volume. After the addition of polymer solution, the suspension was stirred at 250 RPM for $15 \mathrm{~min}$. The flocs were allowed to settle down for 30 minutes. Clean supernatant liquid was drawn from a depth of $1.0 \mathrm{~cm}$ and its turbidity was measured using a digital nephelometer (digital nephelometer model 341 (EI) supplied by ISO-TECH SYSTEM) to express the turbidity in nephelometric unit (NTU). A comparison of flocculation efficiency of guar gum is GG-g-AGA are shown in Figure 3.

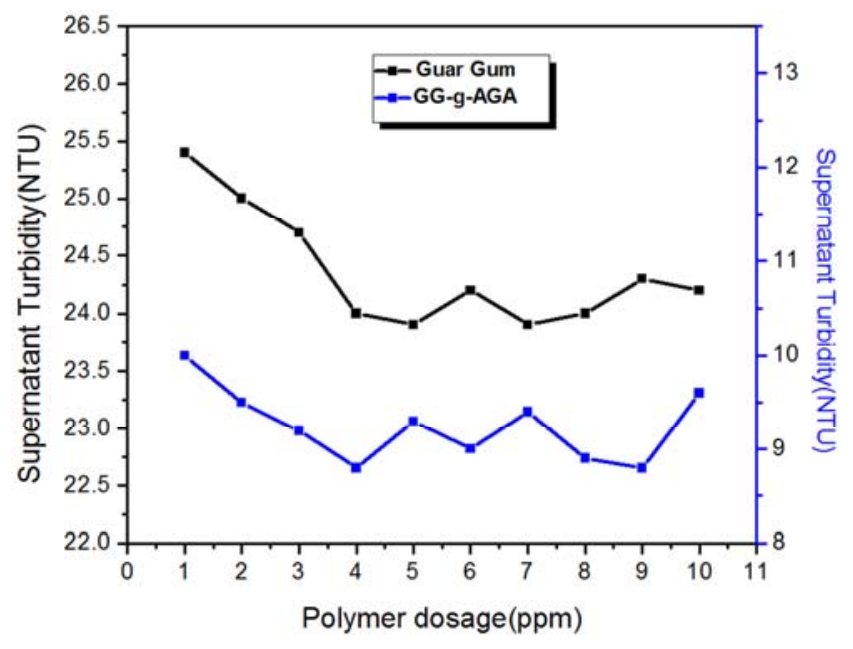

Figure 3. Effect of polymer dosage on turbidity for coking coal.

Plots of supernatant turbidity versus polymer (Guar Gum are GG-g-AGA) dosage for coking is given in Figure 3. It has been found that graft copolymer (GG-g-AGA) shows better performance (lesser turbidity over lowest polymer dose) than guar gum. This could be explained due to the fact that in graft copolymer, the dangling longer poly-PAGA chains have better approachability to the contaminant [2829]. 


\section{Conclusion}

The thermal data shows that the synthesized graft copolymer is thermally more stable than guar gum. The synthesized graft copolymer i.e. GG-g- AGA shows better results for swelling and flocculating properties in comparison to guar gum, this could be interpreted that graft copolymer shows the enhancement in these properties. The spectroscopic data confirm that the grafting of AGA might have taken place at hydroxyl group, which is supported by a tentative mechanism suggested for grafting. The thermal analysis data shows that graft copolymer, a hybrid material in which properties of monomer is added by grafting, could be exploited very well industrially.

\section{Acknowledgement}

One of the authors acknowledges University Grants Commission, for providing financial assistance through Rajiv Gandhi National Fellowship Disability 2013-14 under award letter no. RGNF-2013-14D-GEN-UTT-56934.

Further, the authors are also thankful to UGC, New Delhi, India for providing the Dr. D. S. Kothari Post-doctoral fellowship to Mithilesh Yadav and JMI for providing the various facilities.

\section{References}

[1] Seaman, J. K. (1980). Handbook of water soluble gums and resins. New York: McGraw-Hill.

[2] Thakur V K, M K Thakur. Recent Advances in Graft Copolymerization and Applications of Chitosan: A Review. ACS Sustainable Chem. Eng. 2014, 2, 2637-2652.

[3] Thakur, V. K.; Thakur, M. K.; Gupta, R. K. Graft copolymers of natural fibers for green composites. Carbohydr. Polym. 2014, 104, 87- 93.

[4] Sharma, K., Kaith, B. S., Kumar, V., Kalia, S., Kumar, V. and Swart, H. C. (2014) Water Retention and Dye Adsorption Behavior of Gg-cl-poly (acrylic acid-aniline) Based Conductive Hydrogels. Geoderma, 232-234, 45-55.

[5] Sharma, K., Kumar, V., Kaith, B. S., Som, S., Kumar, V., Pandey, A., Kalia, S. and Swart, H. C. (2015) Synthesis of Biodegradable Gum Ghatti Based Poly (methacrylic acidaniline) Conducting IPN Hydrogel for Controlled Release of Amoxicillin Trihydrate. Industrial \& Engineering Chemistry Research, 54, 1982-1991.

[6] Sacak, M., \& Celik, M. (1996). Hydrogen peroxide initiated grafting of acrylamide onto poly (ethylene terephthalate) fibers in benzyl alcohol. Journal of Applied Polymer Science, $59,1191-1194$.

[7] Raid, G. J. S. (1985). Biochemistry of storage carbohydrates. In P. M. Day, \& R. A. Dixon (Eds.). London: Academic Press.

[8] Wistler, R. L. (1973). Industrial gum. New York: Academic press.

[9] Li, W., Zhao, H., Teasdale, P. R., \& John, R. (2002). Preparation and characterization of poly (2- acrylamidoglycolic acid-coacrylamide) hydrogel for selective binding of $\mathrm{Cu}^{2+}$ and application to diffusive gradients in thin films measurements. Polymer, 43, 4803-4809.

[10] Rivas, B. L., Quilodra`1n, B., \& Quiroz, E. (2003). Removal properties of crosslinked poly (2-acrylamido glycolic acid) for trace heavy metal ions: Effect of $\mathrm{pH}$, temperature, contact time, and salinity on the adsorption behavior. Journal of Applied Polymer Science, 88, 2614-2621.

[11] Rao, K. S. V., Krishna Chung, I., \& Ha, C. S. (2008). Synthesis and characterization of poly (acrylamidoglycolic acid) grafted onto chitosan and its polyelectrolyte complexes with hydroxyapatite. Reactive and Functional Polymer, 68, 943-953.

[12] Durmaz, S., \& Okay, O. (2000). Acrylamide/2-acrylamido-2methylpropane sulfonic acid sodium salt-based hydrogels: Synthesis and characterization. Polymer, 41, 3693-3704.

[13] Rivas, B. L., Martı^ınez, E., Pereira, E., \& Geckeler, K. E. (2001). Synthesis, characterization and poly chelatogenic properties of poly (2-acrylamido-2-methyl-1-propane sulfonic acid)-co- (methacrylic acid)]. Polymer International, 50, 456.

[14] Rivas, B. L., Pereira, E., Cid, R., \& Geckeler, K. E. (2005). Polyelectrolyte-assisted removal of metal ions with ultrafiltration. Journal of Applied Polymer Science, 95, 10911099.

[15] M. Yadav, A. Sand, K. Behari, Journal of Biological Macromolecules. 50 (2012)1306- 1314.

[16] G. F. Fanta, New York, NY/London, England: WileyInterscience. (1973a) 29-45.

[17] Zheng X F, Lian Q, Yang H \& Wang X. Surface Molecularly Imprinted Polymer of Chitosan Grafted Poly (methyl methacrylate) for 5-Fluorouracil and Controlled Release. Scientific Reports, 2016, 6:21409.

[18] D. K. Mishra, J. Tripathy, K. Behari, Carbohydrate Polymers. $71(2008) 524$.

[19] Pandey P K, Srivastava A, Tripathy J, Behari K (2006). Graft copolymerization of acrylic acid onto guar gum initiated by vanadium (V)-mercaptosuccinic acid redox pair Carbohydrate Polymers $65,414-420$.

[20] Doyle, C. D. (1961). Estimating thermal stability of experimental polymers by empirical thermogravimetric analysis. Analytical Chemistry, 33, 77.

[21] Vyazovkin, S., \& Sbirrazzuoli, N. (2006). Isoconversional kinetic analysis of thermally stimulated processes in polymeric macromolecular. Rapid Communications, 27, $1515-1532$.

[22] Chiang, C. L., Chang, R. C., \& Chiu, Y. C. (2007). Thermal stability and degradation kinetics of novel organic/inorganic epoxy hybrid containing nitrogen/silicon/phosphorus by solgel method. Thermochimica Acta, 453, 97-104.

[23] Verma S K, Pandey V S, Yadav M, Behari K. Guar gum-g-N, N-dimethyl acrylamide: Synthesis, characterization and applications. Carbohydrate Polymers 99 (2014) 284- 290.

[24] Harrar H F, Aiouaz N, Dairi N, Hamou A S H. Preparation of Chitosan-g-Poly (acrylamide) / Montmorillonite Superabsorbent Polymer Composites: Studies on Swelling, Thermal, and Antibacterial Properties, J. Appl. Polym. Sci. 2014, DOI: 10.1002/APP. 39747. 
[25] H. F. Zhang, H. Zhong, L. Zhang, S. B. Chen, Y. J. Zhao, Y. Zhu, Carbohydrate Polymers. 77 (2009)785-790.

[26] Zhang, Y., Gu, Q., Yin, J., Wang, Z. and He, P. (2014) Effect of Organic Montmorillonite Type on the Swelling Behavior of Superabsorbent Nanocomposites. Advances in Polymer Technology, 33, Article ID: 21400.

[27] Likhitha, M., Sailaja, R. R. N., Priyambika, V. S. and Ravibabu, M. V. (2014) Microwave Assisted Synthesis of Guar Gum Grafted Sodium Acrylate / Cloisite Superabsorbent
Nanocomposites: Reaction Parameters and Swelling Characteristics. International Journal of Biological Macromolecules, 65, 500-508.

[28] J. Bratby, UK: Uplands Press Ltd. (1980) Chap. 8.

[29] S. R. Deshmukh, R. P. Singh, P. N. Chaturvedi, Journal of Applied Polymer Science. 30 (1985)4013-4018. 